\title{
A primary care medical home approach to pulmonary rehabilitation
}

\author{
Sheena Yurchak RRT, CRE, CTE ${ }^{*}$, Amy Rawlinson RRT, CRE ${ }^{*}$, Jessica Schaub MPH ${ }^{*}$, Yana Ilin Shpilkerman PhD ${ }^{2 *}$, \\ Colleen Makarowski RRT, CRE, CTE ${ }^{*}$, Kirsten Goddard RRT, CRE, CTE ${ }^{1}$, Mohit Bhutani MD, FRCPC, FCCP ${ }^{3}$, \\ Ann-Carol Comeau MN, NP, CCN $(\mathrm{C})^{1}$
}

\begin{abstract}
S Yurchak, A Rawlinson, J Schaub, YI Shpilkerman, C Makarowski, K Goddard, M Bhutani, A-C Comeau. A primary care medical home approach to pulmonary rehabilitation. Can J Respir Ther 2021;57:161-166. doi: 10.29390/cjrt-2021-040

Background: Pulmonary rehabilitation (PR) is an evidence-based, nonpharmacological intervention aimed to improve quality of life for patients living with Chronic Obstructive Pulmonary Disease (COPD). Unfortunately, in Canada, most PR programs are hospital based and these are few in number; therefore, accessibility to PR programs is limited.

Methods: The Edmonton Southside Primary Care Network implemented an evidence-based PR program within the setting of the patient's medical home. Results: Post-program evaluation demonstrated improvement in 6-minute walk distance, lower body strength, COPD health status, and quality of life, as well as a reduction in emergency department visits 1 year after program completion.

Conclusion: The results conclude that delivery of a PR program in a primary care setting is effective and can help address the issue of accessibility.
\end{abstract}

Key Words: self-management; lung diseases; community care; patient care team; program evaluation

\section{INTRODUCTION}

Pulmonary rehabilitation (PR) is an evidence-based, nonpharmacological intervention for management of chronic lung disease that can improve dyspnea, functional capacity, and reduce health care costs through stabilizing or reversing systemic manifestations of such disease $[1,2]$. Involvement of a multidisciplinary health care team for ongoing management provides optimal, collaborative, and individualized patient care $[3,4]$. PR has been widely studied and is a core component of evidence-based treatment plans for those living with Chronic Obstructive Pulmonary Disease (COPD) and has known benefits in the management of those living with chronic lung disease including asthma and interstitial lung disease [5-7]. In Canada, PR is conventionally offered in a hospital-based setting or out-patient community setting resulting in similar patient outcomes [8].

This paper seeks to evaluate patient outcomes of a primary care, patient medical home, referral-based PR program. A literature review did not find any comparable research focused on PR referrals through primary care or PR programs offered within a patient's medical home. Therefore, the authors of this program evaluation agree that research is warranted in this area, comparing conventional versus primary care PR referral pathways and patient outcomes.

In 2013, the COPD prevalence rate in Alberta for those over the age of 40 years was $4.96 \%$ [9]. Although more than 88,000 patients were diagnosed with COPD, the capacity to deliver PR was limited to approximately 1000 patients, with a waiting list for PR services of approximately 400 patients at any given time [9]. The limited accessibility to PR was not unique to Alberta. In 2015, a survey by the Canadian Thoracic Society (CTS) COPD Clinical Assembly reported that only 0.4\% of Canadians with COPD had access to PR programs [1].

Primary Care Networks (PCN) were instituted in Alberta in 2005 through an agreement among Alberta Health, Alberta Health Services, and the Alberta Medical Association to provide team-based collaborative, patient-centred care. Forty-one PCNs across Alberta bring local physicians and multidisciplinary health care professionals together to provide comprehensive patient care within the patient's medical home [10]. In 2011 the College of Family Physicians of Canada (CFPC) released A Vision for Canada: Family Practice - The Patient's Medical Home, a made in Canada, evidence-based vision for the future of primary care by transforming the health care system to better meet the needs of everyone living in Canada [11]. As defined by CFPC, a patient's medical home is a primary care practice defined by its patients as the place they feel most comfortable presenting and discussing their personal and family health and medical concerns [11]. Team-based care is one of the core functions of the patient's medical home. Building a team with a diverse mix of professional backgrounds creates an opportunity to redefine what is considered optimal, based on the needs of the practice and the community it serves. A high-performing team is essential to delivering more comprehensive, coordinated, and effective care centred on the patient's needs [11]. Continuity of care is another core function of the patient's medical home model, which enables and fosters long-term relationships between patients and the care team, thereby ensuring continuous care across the patient's lifespan [11].

\footnotetext{
${ }^{1}$ Edmonton Southside Primary Care Network, Edmonton, $A B$

${ }^{2}$ Health Systems Evaluation $\mathcal{E}$ Evidence, Alberta Health Services, Edmonton, AB

${ }^{3}$ Division of Pulmonary Medicine, Department of Medicine, University of Alberta, Edmonton, AB

*Denotes shared first-authorship.

Correspondence: Sheena Yurchak, Edmonton Southside PCN, 3110 Calgary Trail, Edmonton, AB T6J 6V4, Canada. Tel: 587 598 1726, E-mail: sheena. yurchak@espcn.ca
}

Published online at https://www.cjrt.ca on 23 December 2021

OPEN ACCESS

This open-access article is distributed under the terms of the Creative Commons Attribution Non-Commercial License (CC BY-NC) (http:// creativecommons.org/licenses/by-nc/4.0/), which permits reuse, distribution and reproduction of the article, provided that the original work is properly cited and the reuse is restricted to noncommercial purposes. For commercial reuse, contact editor@csrt.com 
Relational continuity is associated with improvements in preventative care, health, and patient satisfaction, as well as reduced mortality, avoidable hospital services, and cost savings [12, 13]. Edmonton Southside Primary Care Network (ESPCN) operates on a largely decentralized model, where the multidisciplinary team sees patients within the family physician's primary practice. Often, referrals to ESPCN's centrally located programs provide patients with the opportunity to connect with the same multidisciplinary team members and therefore patients may feel that ESPCN central office is an extension of their primary care physician's practice or part of their medical home.

In line with the vision of PCNs and the CTS guidelines for PR, ESPCN sought to develop an accessible, effective, and sustainable PR program in 2012. The program, Breathing for Health (BFH), would utilize a multidisciplinary team approach and work to improve access to PR for patients with chronic lung disease. Providing PR in the setting of a patient's medical home allows opportunity for continuity of care beyond the program, thereby supporting a comprehensive, patient-centred approach to care. This program evaluation aimed to assess whether PR administered in a patient's medical home can improve quality of life, health status and reduce emergency department (ED) visits.

\section{Program overview}

The BFH program is an 8-week, 16-session program providing $1 \mathrm{~h}$ of supervised group exercise and $1 \mathrm{~h}$ of self-management education based on the Living Well with COPD modules (LWWCOPD) [14, 15]; it aligns with the more recently developed Canadian PR standards. A PCN family physician or multidisciplinary team member refers individuals to the program. All referrals must include chest x-ray, electrocardiogram, and pulmonary function test supporting a chronic respiratory condition. The individual is booked into a pre-assessment clinic that includes establishing baseline 6-minute walk distance (6MWD), quality of life scores, and health screening questionnaires. As well, there is a review by the team respirologist to assess suitability and safety to participate in the program. A respiratory therapist and exercise specialist (Clinical Exercise Physiologist) facilitate the program, with additional educational support provided by a dietitian and behavioural health consultants comprised of nurses and social workers. Table 1 provides a summary of the weekly education delivered during the program. The program is located at the ESPCN main office, with use of a dedicated gym space that provides access to a walking track, treadmill, weights, resistance bands, benches, and stationary bikes to fulfill the program's cardiopulmonary and strength exercise components. Step tracker use was introduced to the PR program because of potential health benefits of increased physical activity outside of the 16 PR program sessions [16]. Step tracker data were not collected as part of this program evaluation. To accommodate all severities of lung disease, and to reduce barriers to program attendance, the facility has access to a portable oxygen concentrator for patient use, in addition to their own portable oxygen tanks. The goal of the program is to reduce severity of symptoms and improve the patient's quality of life by increasing exercise tolerance and reducing symptoms, while also promoting independence and behaviour change to make choices in managing their illness.

\section{TABLE 1}

\section{Breathing for Health program content}

\begin{tabular}{ll}
\hline Week & Content \\
\hline 1 & Healthy lifestyles, goal introductions, pretest \\
2 & Lung disease pathology, medication and inhaler device review \\
3 & $\begin{array}{l}\text { Stress management, motivational barriers, breathing management } \\
\text { strategies }\end{array}$ \\
4 & Exercise, nutrition \\
5 & SMART* goals, cough and energy conservation, oxygen therapy \\
6 & Personal directives, enduring power of attorney \\
7 & Aggravating factors, exacerbation management, action plans \\
8 & Goal sharing, questions, celebration, post-exercise commitment, \\
& post-test
\end{tabular}

${ }^{*} \mathrm{~S}$, specific; M, measurable; A, achievable; R, realistic; T, timely.

\section{METHODS}

A pre-post PR program evaluation was conducted to assess the impact of the BFH program for participants completing the program. This program evaluation aimed to assess whether PR administered in a patient's medical home can improve quality of life, health status, and reduce ED visits. End points assessed included change in functional capacity (6MWD), quality of life (St. George's Respiratory Questionnaire and EQ-5D-5L), COPD health status (COPD Assessment Test (CAT)), and lower body strength (30 Second Sit to Stand Test ( $\Delta 30-\mathrm{STST})$ ). Health care utilization (ED visits) due to respiratory causes in the 12 months prior to entry into the PR program and 12 months after program completion was also assessed.

The authors used A Project Ethics Community Consensus Initiative (ARECCI) framework to assess for and mitigate ethical risks, including the ARECCI Ethics Screening Tool and the ARECCI Ethics Guidelines. The project was deemed a program evaluation initiative with a minimal risk. The authors obtained a letter of no objection from the Health Research Ethics Board of Alberta - Community Health Committee.

\section{Data collection instruments \\ Functional capacity}

Higher functional capacity is associated with increased independence, confidence, and quality of life [17-20]. The 6MWD is a practical simple test that measures the distance that a patient can quickly walk on a flat, hard surface in a period of $6 \mathrm{~min}$ [18]. Since the test is self-paced, patients with multiple co-morbidities and varying severity of conditions can perform it safely. Patients are considered in the risk zone if they have walked less than $300 \mathrm{~m}$ [19]. A minimum change of $25 \mathrm{~m}$ in the 6MWD for COPD patients is considered a minimal clinical important difference (MCID) [21].

\section{Lower body strength}

The $\Delta 30$-STST was performed to measure the lower body strength of patients. Research demonstrates that lower body strength helps to improve balance and reduces the risk of falls [22]. In the $\Delta 30$-STST, participants sit on a chair that is $45 \mathrm{~cm}$ from the ground, arms held crossing the chest (unless required to push up for standing), and stand up and sit down as many times as possible in $30 \mathrm{~s}$. The BFH team determined that participants would be considered at risk if fewer than eight unassisted sit-to-stands were completed. A $\Delta 30$-STST of at least two repetitions represents the MCID [23].

\section{COPD health status}

COPD health status was assessed with the CAT, a simple, eight-item health status instrument for patients with COPD. It is highly practical, has good psychometric properties, and has been shown to be responsive to $P R$ and recovery from exacerbation $[24,25]$. A decrease in CAT score represents an improvement in health status, whereas an increase represents worsening. A decrease by two or more points was used as MCID improvement for the CAT $[26,27]$.

\section{Respiratory quality of life}

The St. Georges Respiratory Quality of Life (SGRQ) questionnaire is a disease-specific quality of life assessment tool validated in both COPD and other lung diseases $[28,29]$. The questionnaire measures health status in patients with chronic airflow limitation, with 76 items divided into three parts: symptoms, activity limitation, and social and emotional impact of disease. Scores range from 0 to 100 , where 0 indicates no impairment and 100 indicates worst possible quality of life. A change of 4 points is the MCID for the SGRQ [30-32].

\section{Quality of life}

The EQ-5D-5L is a preference-based health survey assessing five health dimensions with varying levels of severity and overall health visual analog scale (VAS) [33, 34]. The five dimensions include mobility, selfcare, usual activities, pain or discomfort, and anxiety/depression. The EQ-5D-5L yields two scores. The EQ-5D VAS relies on respondents 
choosing a number from 0 (worst imaginable health state) to 100 (best imaginable health state) to indicate their current health state. The EQ-5D index scores (based on the Canadian scoring algorithm) range from -0.148 to 0.949 , with higher scores indicating better health-related quality of life and scores $<0$ indicating a health state "worse than dead", scores $=0$ "same as dead", and scores $>0$ "better than dead" [35]. Research supports an MCID of 10 points change in EQ-5D VAS score and 0.04 points change in EQ-5D Index score [35].

\section{ED visits}

Data were matched from the Group class registration and the National Ambulatory Care Reporting System on The Unique Lifetime Identifier. ED visits due to respiratory causes were extracted for each patient for the 12-months prior to entry into the PR program and 12 months after completion.

Statistical analysis methods

Initially, data were cleaned in Excel and analyzed in SPSS 24 (IBM Corporation). A paired t-test was conducted in SPSS to determine whether there were statistically significant group differences pre- and post-program. An independent $t$-test test was performed for group comparisons and a $\chi^{2}$ test was performed for association testing.

\section{RESULTS}

During the study period, from January 2016 to April 2020, 16 BFH programs were conducted with 209 participants enrolling in the program. In total, almost two-thirds of participants completed the program, as defined internally by the BFH team as any participant who attended minimum $75 \%$ of classes (12 out of 16 ). This was determined using the Global Initiative for Chronic Obstructive Lung Disease guidelines at the time, which stated the minimum length of an effective rehabilitation program is 6 weeks with supervised exercise at minimum twice a week [36]. Pre- and post-data were analysed for participants with pre- and post-measures available.

\section{Demographics}

The mean age of patients enrolled in the program was 71 years, and just over half were male. Table 2 shows the baseline characteristics of all patients attending at least one class. Most of the patients had a diagnosis of COPD. Almost two-thirds of enrollees had three or more co-morbidities. One-fifth of participants were current smokers, while almost three-quarters were ex-smokers. Those patients who completed the program had higher representation of male participants compared with those who did not complete or cancelled their participation in the program. No other differences in patient characteristics and completion level were statistically significant.

\section{Program impacts}

Program impacts were calculated only for those patients who had post-program data available for comparisons. Descriptive statistics and significance between pre- and post-program data are highlighted in Table 3.

Pretests of functional status, measured by the 6MWD, classified 28 participants in the risk zone with 17 of these participants (61\%) moved post-program into the nonrisk zone. Almost three-quarters (72\%) of participants showed clinically meaningful improvements in their functional capacity, increased walking distance at least $25 \mathrm{~m}$, after program completion. Overall, participants showed a significant increase in the number of meters walked $(p<0.01)$.

Positive changes were observed for lower body strength, as measured by the $\Delta 30$-STST test. Pretests classified 24 participants in the risk zone (fewer than eight unassisted sit-to-stands; cut off provided by team), and of those 19 (79\%) moved into the nonrisk zone post-program. Over half of participants (54\%) showed clinically meaningful improvements in lower body strength. Overall, participants significantly increased the number of sit-to-stands after the pro$\operatorname{gram}(p<0.01)$.
Half the participants showed clinically meaningful improvement in COPD health status. CAT scores significantly improved (decreased) after the program $(p<0.01)$.

Nearly half (42\%) the participants showed clinically meaningful improvement in their respiratory quality of life. However, no statistically significant difference was observed in the SGQL pre- versus post-assessment. Positive change was also observed in the EQ-5D-5L health survey. Over one-third of participants showed clinically

\section{TABLE 2}

Breathing for health participant demographics

\begin{tabular}{|c|c|c|c|c|}
\hline Demographic & $\begin{array}{c}\text { Total } \\
(n=209), \\
N(\%)\end{array}$ & $\begin{array}{l}\text { Completed } \\
\text { program } \\
(n=132), \\
N(\%)\end{array}$ & $\begin{array}{l}\text { Incomplete } \\
\text { or cancelled } \\
\begin{array}{c}(n=77) \\
N(\%)\end{array}\end{array}$ & $p$ \\
\hline Gender & & & & $<0.05$ \\
\hline Male & $107(51)$ & $75(57)$ & $32(42)$ & \\
\hline Age, $y$ & & & & n.s. \\
\hline$<60$ & $24(12)$ & $14(11)$ & $10(13)$ & \\
\hline $60-79$ & $147(70)$ & $99(75)$ & $48(62)$ & \\
\hline $80+$ & $38(18)$ & 19 (15) & $19(25)$ & \\
\hline Smoking status & & & & n.s. \\
\hline Current smoker & $30(14)$ & $19(14)$ & $11(14)$ & \\
\hline Ex-smoker & $116(56)$ & $95(72)$ & $21(27)$ & \\
\hline Nonsmoker & $15(7)$ & $13(10)$ & $2(3)$ & \\
\hline Missing & $48(23)$ & $5(4)$ & $43(56)$ & \\
\hline \multicolumn{4}{|c|}{ Number of comorbidities per patient } & n.s. \\
\hline $\begin{array}{l}\text { COPD or Asthma } \\
\text { Only }\end{array}$ & $10(5)$ & $9(7)$ & $1(1)$ & \\
\hline 1 & $28(13)$ & $24(18)$ & $4(5)$ & \\
\hline 2 & $25(12)$ & $18(14)$ & $7(9)$ & \\
\hline 3 & $38(18)$ & $26(20)$ & $12(16)$ & \\
\hline 4 & $30(14)$ & $24(18)$ & $6(8)$ & \\
\hline $5+$ & $34(16)$ & $30(23)$ & $4(5)$ & \\
\hline Missing & $44(21)$ & $1(1)$ & $43(56)$ & \\
\hline $\begin{array}{l}\text { Comorbidity } \\
\text { diagnosis }\end{array}$ & & & & n.s. \\
\hline Hypertension & $94(45)$ & $71(54)$ & $23(30)$ & \\
\hline $\begin{array}{l}\text { Dyslipidemia, } \\
\text { hyperlipidemia, } \\
\text { hypercholesterol- } \\
\text { emia }\end{array}$ & $73(35)$ & $62(47)$ & $11(14)$ & \\
\hline $\begin{array}{l}\text { Gastroesophageal } \\
\text { reflux disease }\end{array}$ & $52(25)$ & $40(30)$ & $12(16)$ & \\
\hline Arthritis & $52(25)$ & $38(29)$ & $14(18)$ & \\
\hline $\begin{array}{l}\text { Coronary artery } \\
\text { disease }\end{array}$ & $36(17)$ & $29(22)$ & $7(9)$ & \\
\hline Anxiety & $34(16)$ & $27(21)$ & $7(9)$ & \\
\hline Depression & $33(16)$ & $26(20)$ & $7(9)$ & \\
\hline Hypothyroidism & $29(14)$ & $21(16)$ & $8(10)$ & \\
\hline Sleep apnea & $29(14)$ & $26(20)$ & $3(4)$ & \\
\hline Diabetes & $27(13)$ & $21(16)$ & $6(8)$ & \\
\hline Osteoporosis & $23(11)$ & $17(13)$ & $6(8)$ & \\
\hline Pulmonary fibrosis & $10(5)$ & $9(7)$ & $1(1)$ & \\
\hline Other* & $29(14)$ & $25(19)$ & $4(5)$ & \\
\hline
\end{tabular}

*Includes comorbidities such as: hiatus hernia, transient ischemic attack, diverticulosis, chronic kidney disease, glaucoma, polymyalgia rheumatic, obesity hypoventilation symptom, thyroid disease, and/or bipolar disorder. 
meaningful improvements in their EQ-5D-5L index and EQ-5D-5L VAS (42\% and 34\%, respectively). Differences for both the EQ-5D-5L index and EQ-5D VAS were statistically significant $(p<0.05)$.

The average number of ED visits related to disease of the respiratory system 12 months after program registration was compared to average preprogram ED visits. Table 4 shows the frequencies and significance between pre-and post-program data for ED visits. Across all participants, post-program ED visits statistically decreased from 1.6 to 1.0 $(p<0.05)$. An even greater decline in average ED visits was observed for participants who completed the program (1.9 to $1.1, p<0.05)$.

\section{DISCUSSION}

For patients that live with lung disease, the combination of the nonpharmacological and pharmacological strategies is critical for improving outcomes. The role of PR, although has primarily focused on COPD, is evolving to show benefit in the outcomes of other lung-related illnesses, such as severe asthma or pulmonary hypertension, interstitial lung disease and even lung cancers. However, access to these programs is limited. The BFH PR program is a first of its kind program to deliver PR in the patient's medical home. This novel approach provides several advantages to PR delivery including familiarity of the patients with the PR staff members, education and exercise in familiar environments and primary care support as this program is endorsed by the PCN that they belong to. This improved

\section{TABLE 3}

Descriptive statistics and significance between pre- and post-program data for 6MWD, $\triangle 30-\mathrm{STST}, \mathrm{CAT}, \mathrm{SGQL}$, and EQ-5D (Index and VAS)*

\begin{tabular}{|c|c|c|c|c|}
\hline Assessment Tool & $n$ & $\begin{array}{l}\text { Pre-mean (STD) } \\
\text { min.-max. }\end{array}$ & $\begin{array}{l}\text { Post-mean (STD) } \\
\text { min.-max. }\end{array}$ & $p$ \\
\hline \multicolumn{5}{|c|}{ Functional Capacity (6MWD) } \\
\hline $\begin{array}{l}\text { At risk }(<300 \mathrm{~m}) \text { at the } \\
\text { beginning }\end{array}$ & 28 & $\begin{array}{l}237(62) \\
84-294\end{array}$ & $\begin{array}{l}296(75) \\
84-405\end{array}$ & $<0.05$ \\
\hline Overall & 126 & $\begin{array}{l}374(102) \\
84-585\end{array}$ & $\begin{array}{c}435(115) \\
84-756\end{array}$ & $<0.05$ \\
\hline \multicolumn{5}{|c|}{ Lower Body Strength ( $\Delta 30-\mathrm{STST})$} \\
\hline $\begin{array}{l}\text { Less than } 8 \text { reps (at risk } \\
\text { at the beginning) }\end{array}$ & 24 & $6.2(1.0)$ & $9.3(2.8)$ & $<0.05$ \\
\hline $\begin{array}{l}\text { Between } 8 \text { to } 10 \text { reps } \\
\text { (at the beginning) }\end{array}$ & 54 & $8.9(0.8)$ & $11.1(2.4)$ & $<0.05$ \\
\hline $\begin{array}{l}\text { More than } 11 \text { reps (at } \\
\text { the beginning) }\end{array}$ & 44 & $12.7(1.9)$ & $13.6(3.0)$ & n.s. \\
\hline Overall & 122 & $\begin{array}{l}9.8(2.8) \\
3-20\end{array}$ & $\begin{array}{c}11.6(3.1) \\
4-22\end{array}$ & $<0.05$ \\
\hline \multicolumn{5}{|c|}{ COPD Health Status (CAT) } \\
\hline Overall & 105 & $\begin{array}{c}17.4(6.9) \\
2-32\end{array}$ & $\begin{array}{c}15.6(6.5) \\
3-31\end{array}$ & $<0.05$ \\
\hline \multicolumn{5}{|c|}{ Respiratory Quality of Life (SGRQ) } \\
\hline Symptom & 67 & $53.7(22.2) 0-100$ & $\begin{array}{c}52.1(21.8) \\
2-91\end{array}$ & n.s. \\
\hline Activity & 67 & $\begin{array}{c}60.3(22.4) \\
0-94\end{array}$ & $\begin{array}{c}57.5(24.5) \\
0-100\end{array}$ & n.s. \\
\hline Impact & 67 & $\begin{array}{c}30.2(18.0) \\
0-85\end{array}$ & $\begin{array}{c}29.9(20.7) \\
0-87\end{array}$ & n.s. \\
\hline Overall & 67 & $\begin{array}{c}43.2(17.8) \\
4.8-84\end{array}$ & $\begin{array}{l}40.6(18.5) \\
3-75\end{array}$ & n.s. \\
\hline \multicolumn{5}{|l|}{ Quality of Life (EQ-5D-5L) } \\
\hline EQ-5D Index & 117 & $\begin{array}{l}0.77(0.17) \\
0.08-0.95\end{array}$ & $\begin{array}{l}0.8(0.15) \\
0.14-0.95\end{array}$ & $<0.05$ \\
\hline EQ-5D VAS & 117 & $\begin{array}{l}67(18.3) \\
30-100\end{array}$ & $\begin{array}{c}70(16.1) \\
20-100\end{array}$ & $<0.05$ \\
\hline
\end{tabular}

Note: 6 MWD, six minute walk distance; $\triangle 30$-STST, 30 second sit to stand test; CAT, COPD assessment test; SGQL, St. George's respiratory quality of life questionnaire.

*Includes only patients that have both pre- and post-measurement. knowledge translation to primary care physicians regarding the role PR plays in the treatment of patients with chronic respiratory diseases is of clear advantage to improve practice patterns. In addition, there is routinely a large waitlist for PR programs in Alberta, approximately 400 patients at any point [9]. ESPCN patients can have faster access to $\mathrm{PR}$, due to a potentially smaller waitlist, as the program is prioritized for patients belonging to ESPCN. The BFH patient referrals come from family physicians, respiratory therapists, and other clinicians in the patient's medical home. These are all strengths of the BFH program and is in keeping with current CTS recommendations for patients to attend PR if they have persistent symptoms, poor exertional capability, and health status despite optimized pharmacotherapy [37].

Education materials delivered during the program are consistent with Canadian PR standards. LWWCOPD course booklets are provided, and facilitators utilize prepared presentations that cover subjects such as lung anatomy and physiology, lung disease pathophysiology, medication and inhaler device techniques, energy conservation principles, and breathing management strategies [15]. As part of the patient's medical home, patients receive tailored presentations on nutrition by a registered dietitian, improvement of physical activity with an exercise specialist, stress and anxiety management with a behavioural health consultant, and have the option to complete enduring power of attorney, personal directives, and goals of care with a healthy-aging social worker. These presentations allow for open discussion specific to patient concerns and help facilitate future one-on-one follow-up with these clinicians within their medical home.

Program graduates are offered a variety of additional exercise-specific programs offered by ESPCN including a once per week open gym with exercise specialist supervision. BFH participants may also access one-onone follow-up care with any member of the multidisciplinary team. This patient-centred approach allows patients to address health care goals most important to them. A consistent six-month follow up was recently implemented in line with CTS recommendations, which will allow for continued support from within the patient's medical home. At the sixmonth follow-up, patients are asked about their activity level, changes in medication, health status, and health care utilization. Program-specific surveys are re-administered, and an updated functional assessment is completed.

Limitations and future considerations

Several limitations need to be considered when interpreting the findings. First, a sampling bias cannot be ruled out as we lack information about those participants who were eligible to participate but did not receive referral to the program. Moreover, over one-third of the program registrants did not complete the program. More investigation is warranted to understand why some participants do not complete the program. There is a lack of data that states acceptable participant drop out rates for similar PR programs. However, ESPCN completion rates are consistent with other PR studies in Canada [8]. In addition, we do have missing data as our evaluation used available program data and did not have a highly controlled environment that is typical of many research studies.

\section{TABLE 4}

Frequency and significance between pre- and post-program data for emergency department visits

\begin{tabular}{lcccc}
\hline $\begin{array}{l}\text { 12-month } \\
\text { pre- versus } \\
\text { post-program }\end{array}$ & $\boldsymbol{n}$ & $\begin{array}{c}\text { Pre-mean (STD) } \\
\text { min.-max, }\end{array}$ & $\begin{array}{c}\text { Post- mean (STD) } \\
\text { min.-max. }\end{array}$ & $\boldsymbol{p}$ \\
\hline Completed & 58 & $1.9(2.4)$ & $1.2(1.5)$ & $<0.05$ \\
program & & $0-11$ & $0-5$ & \\
Incomplete/ & 37 & $1.1(0.8)$ & $0.8(1.2)$ & n.s. \\
cancelled & & $0-4$ & $0-6$ & \\
Overall & 95 & $1.6(2.1)$ & $1.0(1.4)$ & $<0.05$ \\
& & $0-11$ & $0-6$ & \\
\hline
\end{tabular}




\section{CONCLUSION}

Program evaluation is a valuable tool to assess program impacts, as well as improve the quality of programs. Program evaluation of PR would be strengthened by mixed-methods approaches, for example, the use of qualitative participant and facilitator feedback data to inform program improvements. Expanding the evaluation plan to include post-graduation data at six months or beyond allows for assessment of the longevity of the program benefits and provides an opportunity to reconnect patients with their primary care team.

The current COVID-19 pandemic has highlighted the need for continued optimization of telehealth or other virtual PR delivery platforms [38]. Prior to the pandemic, some BFH attendees did not complete the full program due to a variety of barriers to in-person attendance such as transportation and mobility. During the pandemic, $\mathrm{BFH}$ has transitioned into virtual programming that includes LWWCOPD education, guest-speaker presentations, and a modified exercise program to support those with chronic lung conditions. Virtual/telehealth programing supports patients with chronic lung disease by improving health-related quality of life and overall exertional capability comparable to in-person programing [39]. More research is warranted to understand its role in reduction of health care utilization and exacerbation recognition [40].

Overall, the delivery of the BFH program through a primary care site has increased local access to PR for patients. Evaluation results indicate the BFH program supports improvements in functional capacity, lower body strength, COPD health status, respiratory quality of life, and quality of life for the participants completing the program. Additionally, a decrease in ED visits for program participants was observed. Providing program access through primary care improves self-management of lung disease and overall improvement in patient quality of life, while connecting patients to other team members in their medical home.

\section{DISCLOSURES}

\section{Acknowledgements}

The authors would like to thank Tye Babb BPE, BSc, CSEP Certified Exercise Physiologist, for his significant contributions to our pulmonary rehabilitation program. The authors would also like to thank the Edmonton Southside PCN as a whole for their ongoing support and especially our data management team for their help in collecting, organizing and analyzing our program data.

\section{Competing interests}

All authors have completed the ICMJE uniform disclosure form at www. icmje.org/coi_disclosure.pdf and declare: no financial relationships with any organizations that might have an interest in the submitted work in the previous 3 years; no other relationships or activities that could appear to have influenced the submitted work.

\section{Funding \\ Not applicable.}

\section{Ethical approval}

The authors used A pRoject Ethics Community Consensus Initiative (ARECCI) framework to assess for and mitigate ethical risks, including the ARECCI Ethics Screening Tool and the ARECCI Ethics Guidelines. The project was deemed a program evaluation initiative with a minimal risk. The authors obtained a letter of no objection from the Health Research Ethics Board of Alberta - Community Health Committee.

\section{REFERENCES}

1. Camp PG, Hernandez P, Bourbeau J, et al. Pulmonary rehabilitation in Canada: a report from the Canadian Thoracic Society COPD Clinical Assembly. Can Resp J 2015;22(3):147-52. doi: 10.1155/2015/369851.

2. Nici L, Donner C, Wouters E, et al. American Thoracic Society/European Respiratory Society statement on pulmonary rehabilitation. Am J Respir Crit Care Med 2006;173(12):1390-413. doi: 10.1164/rccm.200508-1211ST.
3. Dinh T, Bounajm F. Improving primary health care through collaboration. Briefing 3: measuring the missed opportunity. Ottawa: The Conference Board of Canada; 2013. Available at: https://www.conferenceboard. ca/e-Library/abstract.aspx?did=5479 (Accessed April 19, 2021).

4. The College of Family Physicians of Canada. Team-based care in the patient's medical home. Best Advice. Mississauga, ON: College of Family Physicians of Canada; 2017. Available at: https://patientsmedicalhome. $\mathrm{ca} /$ resources/best-advice-guides/best-advice-guide-team-based-care-patients-medical-home/ (Accessed April 19, 2021).

5. Dechman G, Hernandez P, Camp PG. Exercise prescription practices in pulmonary rehabilitation programs. Can J Respir Crit Care Sleep Medi 2017;1(2):77-83. doi: 10.1080/24745332.2017.1328935.

6. Dowman L, Hill CJ, Holland AE. Pulmonary rehabilitation for interstitial lung disease. Cochrane Database Syst Rev 2014 Oct 6;10:CD006322. doi: 10.1002/14651858.CD006322.pub3.

7. Spruit MA, Singh SJ, Garvey C, et al. An official American thoracic society/European respiratory society statement: key concepts and advances in pulmonary rehabilitation. Am J Respir Crit Care Med 2013;188:e13-64. doi: 10.1164/rccm.201308-1509ST.

8. Marciniuk DD, Brooks D, Butcher S, et al. Optimizing pulmonary rehabilitation in chronic obstructive pulmonary disease-practical issues: a Canadian Thoracic Society Clinical Practice Guideline. Can Respir J 2010;17(4):159-68. doi: 10.1155/2010/4259759.

9. Waye AE, Jacobs P, Ospina MB, Stickland MK, Mayers I. Economic surveillance for chronic obstructive pulmonary disease (COPD) in Alberta. Edmonton, AB: Institute of Health Economics; 2016. Available at: http://www.ihe.ca (Accessed February 2, 2021).

10. Alberta: Primary Care networks Program Management Office; c2021. Available at: https://pcnpmo.ca/alberta-pcns (Accessed February 6, 2021).

11. College of Family Physicians of Canada. A new vision for Canada: family practice - the patient's medical home 2019. Mississauga, ON: College of Family Physicians of Canada; 2019. Available at: https://patientsmedicalhome.ca/files/uploads/PMH_VISION2019_ENG.pdf (Accessed March 16, 2021).

12. Canadian Institute for Health Information. Continuity of care with family medicine physicians: why it matters. Available at: https://secure.cihi.ca/ free_products/UPC_ReportFINAL_EN.pdf (Accessed April 19, 2021).

13. Alberta Medical Association. Evidence summary: the benefits of relational continuity in primary care 2017 Update. Available at: https://actt. albertadoctors.org/file/top--evidence-summary-value-of-continuity.pdf (Accessed April 5, 2021).

14. Dechman G, Cheung W, Ryerson CJ, et al. Quality indicators for pulmonary rehabilitation programs in Canada: a Canadian Thoracic Society expert working group report. Can J Respir Crit Care Sleep Med 2019;3(4):199-209. doi: 10.1080/24745332.2019.1643610.

15. Canadian pulmonary rehabilitation program. c2021. Available at: https://www.livingwellwithcopd.com/canadian-pulmonary-rehabilitation-program.html (Accessed February 6, 2021).

16. Bravata DM, Smith-Spangler C, Sundaram V, et al. Using pedometers to increase physical activity and improve health: a systematic review. JAMA 2007 Nov;21:2296-304. doi: 10.1001/jama.298.19.2296. PMID: 18029834.

17. Chambela MC, Mediano MFF, Ferreira RR, et al. Correlation of 6-min walk test with left ventricular function and quality of life in heart failure due to Chagas disease. Trop Med Int Health 2017 Oct;22(10):1314-21. doi: 10.1111/tmi.12939. Epub 2017 Sep 5. PMID: 28805026.

18. ATS Committee on Proficiency Standards for Clinical Pulmonary Function Laboratories. ATS statement: guidelines for the six-minute walk test. Am J Respir Crit Care Med 2002 Jul 1;166(1):111-7. doi: 10.1164/ ajrccm.166.1.at1102. Erratum in: Am J Respir Crit Care Med 2016 May 15;193(10):1185. doi: 10.1164/ajrccm.166.1.at1102. PMID: 12091180.

19. Faggiano P, D’Aloia A, Gualeni A, Brentana L, Dei Cas L. The 6 minute walking test in chronic heart failure: indications, interpretation and limitations from a review of the literature. Eur J Heart Fail 2004 Oct;6(6):687-91. doi: 10.1016/j.ejheart.2003.11.024. PMID: 15542403.

20. Peddle-McIntyre CJ, Singh F, Thomas R, Newton RU, Galvão DA, Cavalheri V. Exercise training for advanced lung cancer. Cochrane Database Syst Rev 2019 Feb 11;2(2):CD012685. doi: 10.1002/14651858. CD012685.pub2. PMID: 30741408; PMCID: PMC6371641.

21. Holland AE, Hill CJ, Rasekaba T, Lee A, Naughton MT, McDonald CF. Updating the minimal important difference for six-minute walk distance in patients with chronic obstructive pulmonary disease. Arch Phys Med Rehabil 2010 Feb;91(2):221-5. doi: 10.1016/j.apmr.2009.10.017. PMID: 20159125. 
22. Ishigaki EY, Ramos LG, Carvalho ES, Lunardi AC. Effectiveness of muscle strengthening and description of protocols for preventing falls in the elderly: a systematic review. Braz J Phys Ther $2014 \mathrm{Mar}-\mathrm{Apr} ; 18(2): 111-8$. doi: 10.1590/s1413-35552012005000148. Epub 2014 Apr 22. PMID: 24760166; PMCID: PMC4183251.

23. Zanini A, Crisafulli E, D’Andria M, et al. Minimum clinically important difference in 30-s sit-to-stand test after pulmonary rehabilitation in subjects with COPD. Respir Care 2019 Oct;64(10):1261-9. doi: 10.4187/ respcare.06694. Epub 2019 Jul 3. PMID: 31270178.

24. Gupta N, Pinto LM, Morogan A, Bourbeau J. The COPD assessment test: a systematic review. Eur Respir J 2014 Oct;44(4):873-84. doi: 10.1183/09031936.00025214. Epub 2014 Jul 3. PMID: 24993906.

25. Lee SD, Huang MS, Kang J, et al. Investigators of the predictive ability of CAT in acute exacerbations of COPD (PACE) study. The COPD assessment test (CAT) assists prediction of COPD exacerbations in high-risk patients. Respir Med 2014 Apr;108(4):600-8. doi: 10.1016/j. rmed.2013.12.014. Epub 2014 Jan 6. PMID: 24456695.

26. Kon SS, Canavan JL, Jones SE, et al. Minimum clinically important difference for the COPD assessment test: a prospective analysis. Lancet Respir Med 2014 Mar;2(3):195-203. doi: 10.1016/S2213-2600(14)700013. Epub 2014 Feb 4. PMID: 24621681.

27. Jo YS, Yoon HI, Kim DK, Yoo CG, Lee CH. Comparison of COPD assessment test and clinical COPD questionnaire to predict the risk of exacerbation. Int J Chron Obstruct Pulmon Dis 2017 Dec 22;13:101-7. doi: 10.2147/COPD.S149805. PMID: 29317814; PMCID: PMC5744740.

28. El Rhazi K, Nejjari C, Benjelloun MC, et al. Validation of the St. George's Respiratory Questionnaire in patients with COPD or asthma in Morocco. Int J Tuberc Lung Dis 2006 Nov;10(11):1273-8. PMID: 17131788.

29. Meguro M, Barley EA, Spencer S, Jones PW. Development and validation of an improved, COPD-specific version of the St. George Respiratory Questionnaire. Chest 2007 Aug;132(2):456-63. doi: 10.1378/chest.060702. Epub 2007 Jul 23. PMID: 17646240.

30. Jones PW. Interpreting thresholds for a clinically significant change in health status in asthma and COPD. Eur Respir J 2002 Mar; 19(3):398-404. doi: 10.1183/09031936.02.00063702. PMID: 11936514.

31. Jones PW, Brusselle G, Dal Negro RW, et al. Health-related quality of life in patients by COPD severity within primary care in Europe. Respir Med 2011 Jan;105(1):57-66. doi: 10.1016/j.rmed.2010.09.004. Epub 2010 Oct 6. PMID: 20932736.
32. Hardin M, Rennard SI. What's new with the St George's Respiratory Questionnaire and why do we care? Chronic Obstr Pulm Dis 2017 Apr 3;4(2):83-6. doi: 10.15326/jcopdf.4.2.2017.0139. PMID: 28848916; PMCID: PMC5559106.

33. EuroQol Group. EuroQol - a new facility for the measurement of health-related quality of life. Health Policy 1990 Dec;16(3):199-208. doi: 10.1016/0168-8510(90)90421-9. PMID: 10109801.

34. Herdman M, Gudex C, Lloyd A, et al. Development and preliminary testing of the new five-level version of EQ-5D (EQ-5D-5L). Qual Life Res 2011 Dec;20(10):1727-36. doi: 10.1007/ s11136-011-9903-x. Epub 2011 Apr 9. PMID: 21479777; PMCID: PMC3220807.

35. McClure NS, Sayah FA, Xie F, Luo N, Johnson JA. Instrument-defined estimates of the minimally important difference for EQ-5D-5L index scores. Value Health 2017 Apr;20(4):644-50. doi: 10.1016/j. jval.2016.11.015. Epub 2017 Jan 10. PMID: 28408007.

36. Global Initiative for Chronic Obstructive Lung Disease (GOLD). Global strategy for diagnosis, management and prevention of COPD. 2017. Available at: https://goldcopd.org/wp-content/ uploads/2017/02/wms-GOLD-2017-FINAL.pdf (Accessed April 19, 2021).

37. Bourbeau J, Bhutani M, Hernandez P, et al. Canadian Thoracic Society Clinical Practice Guideline on pharmacotherapy in patients with COPD - 2019 update of evidence. Can J Respir Crit Care Sleep Med 2019;3(4):210-32. doi: 10.1080/24745332.2019. 1668652.

38. Dechman G, Aceron R, Beauchamp M, et al. Delivering pulmonary rehabilitation during the COVID-19 pandemic: a Canadian Thoracic Society position statement. Can J Respi Crit Care Sleep Med 2020;4(4):232-5. doi: 10.1080/24745332.2020.1828683.

39. Stickland M, Jourdain T, Wong EY, Rodgers WM, Jendzjowsky NG, Macdonald FG. Using telehealth technology to deliver pulmonary rehabilitation in chronic obstructive pulmonary disease patients. Can Respir J 2011;18(4):216-20. doi: 10.1155/2011/640865.

40. Selzler AM, Wald J, Sedeno M, et al. Telehealth pulmonary rehabilitation: A review of the literature and an example of a nationwide initiative to improve the accessibility of pulmonary rehabilitation. Chron Respir Dis 2018 Feb;15(1):41-7. doi: 10.1177/147997231 7724570 . 